\title{
Influência do substrato e do enraizamento na aclimatização de Melocactus glaucescens Buining \& Brederoo propagados in vitro ${ }^{1}$
}

\author{
Sheila Vitória Resende²; Alone Lima-Brito ${ }^{3}$ José Raniere Ferreira de Santana ${ }^{4}$
}

\section{RESUMO}

Melocactus glaucescens (Cactaceae) é espécie endêmica da Bahia e está incluída na lista da IUCN e MMA como ameaçada de extinção. A transferência da condição in vitro para o ambiente ex vitro é uma etapa crítica, podendo ser um fator limitante para a produção das mudas micropropagadas. O objetivo deste trabalho foi analisar o efeito de diferentes substratos e do enraizamento na aclimatização de Melocactus glaucescens. As plantas propagadas in vitro foram mantidas sob $100 \%$ de luminosidade, com regas diárias por 75 dias. Os resultados demonstraram que o substrato adequado para a aclimatização deve conter 50\% de terra vegetal e 50\% de areia lavada; o tamanho mínimo do diâmetro e do comprimento da parte aérea para transferência para as condições ex vitro é de $5 \mathrm{~mm}$ e que as etapas de enraizamento in vitro e rustificação podem ser eliminadas da micropropagação de M. glaucescens. Estudos para demonstrar tempos de dessecação dos brotos acima de $5 \mathrm{~mm}$ são necessários, para se eliminar completamente a etapa do enraizamento in vitro para esta espécie.

Palavras-chave: Cabeça-de-frade, cacto, condição ex vitro, cultivo in vitro.

\section{ABSTRACT}

\section{Effect of substrate and rooting on acclimatization of in vitro propagated Melocactus glaucescens Buining \& Brederoo}

Melocactus glaucescens (Cactaceae) is endemic to Bahia and is included in the IUCN and MMA lists as endangered species. Transference of in vitro cultures to ex vitro environment is critical and can become limiting for the production of micropropagated scions. The main objective of this work was to examine the effect of different substrates and rooting during acclimatization of Melocactus glaucescens. The plants were in vitro propagated and kept in $100 \%$ light, on daily cycles for 75 days. The results suggested that the best substrate should consist of $50 \%$ soil and $50 \%$ sand; plantlets should be at least $5 \mathrm{~mm}$ in diameter and height before being transferred; and that both steps in vitro rooting and harding could be eliminated from micropropagation of $M$. glaucescens. Further studies are still needed on desiccation time of shoots above $5 \mathrm{~mm}$ so that the step of in vitro rooting can be completely eliminated.

Key words: Cabeça-de-frade, cactus, ex vitro environment, in vitro culture

\footnotetext{
Recebido para publicação em março de 2010 e aprovado em outubro de 2010

${ }^{1}$ Parte da Tese de Doutorado da primeira autora

Bióloga, Doutora. Universidade Federal da Bahia, Rua Barão de Geremoabo s/n, Instituto de Biologia, Laboratório de Cultura de Tecidos Vegetais, Ondina, 40170-115, Salvador,

Bahia, Brasil. svresende@yahoo.com.br Autor para correspondência

${ }^{3}$ Bióloga, Doutora. Universidade Estadual Feira de Santana - Laboratório de Cultura de Tecidos Vegetais, Caixa Postal 252-294, 44031-460, Feira de Santana, Bahia, Brasil. lima_brito@yahoo.com.br

${ }^{4}$ Engenheiro-Agrônomo, Doutor. Universidade Estadual Feira de Santana - Laboratório de Cultura de Tecidos Vegetais, Caixa Postal 252-294, 44031-460, Feira de Santana, Bahia, Brasil. raniere@uefs.br
} 


\section{INTRODUÇÃO}

O gênero Melocactus (L.) Link \& Otto (Cactaceae), conhecido como cabeça-de-frade ou coroa-de-frade, possui 37 espécies, sendo 11 espécies e 4 subespécies endêmicas da Bahia (Machado, 2009). Melocactus glaucescens Buining \& Brederoo é endêmica da região de Morro do Chapéu, ocorrendo em uma pequena área de cerca de $10 \mathrm{~km}^{2}$, sendo conhecidas apenas quatro populações, com um número reduzido de indivíduos (Taylor 2000; Taylor \& Zappi, 2004).

A lista do Ministério do Meio Ambiente inclui cinco espécies de Melocactus ameaçadas de extinção, todas endêmicas do Estado da Bahia, como M. glaucescens, que também está incluída na lista de espécies ameaçadas da The IUCN Red List of Threatened Species (MMA, 2008; IUCN, 2010).

Muitas espécies do gênero Melocactus são coletadas de forma extrativista para fabricação de doces, utilização na medicina tradicional e comercialização como planta ornamental, o que tem levado a uma redução das plantas em seu habitat (Lambert 2006a e b; Lone et al., 2009). O fato de os indivíduos serem removidos inteiros da natureza agrava a ameaça de extinção (Fonseca, 2004).

A micropropagação é uma das técnicas da cultura de tecidos vegetais mais utilizadas e que permite altas taxas de multiplicação em curto período, espaço reduzido e plantas livres de patógenos (Estrada-Luna et al., 2008). Para as espécies da família Cactaceae, o cultivo in vitro, além de acelerar o crescimento das plantas, resultante da fixação continua de $\mathrm{CO}_{2}$ durante os períodos diurno e noturno, possibilita uma alternativa à retirada dos indivíduos do seu habitat para a comercialização como planta ornamental e, consequentemente, reduz as pressões sobre as populações naturais (Escobar et al., 1986; Hubstenberger et al., 1992; Malda et al.,1999; RetesPruneda et al., 2007).

Para as plantas obtidas in vitro, é necessário um período de aclimatização, após a remoção do ambiente in vitro, o que permitirá sua sobrevivência nas condições de cultivo em campo (Barboza et al., 2006). A transferência da condição in vitro para o ambiente ex vitro é a etapa mais crítica da micropropagação, podendo ser um fator limitante para a produção das mudas micropropagadas de algumas espécies, pois as plantas são expostas a mudanças súbitas nas condições ambientais, sendo a perda de água o principal problema (Grattapaglia \& Machado 1998; Rocha et al., 2008).

A escolha de um substrato adequado reduz a mortalidade das plantas durante a aclimatização (Moreira et al., 2006). O substrato exerce influência na arquitetura do sistema radicular e no estado nutricional das plantas; deve ter, portanto, a capacidade de reter umidade e de não se compactar excessivamente, o que pode comprometer a drenagem do excesso de água durante as irrigações e a manutenção da aeração do sistema radicular, a fim de possibilitar o desenvolvimento satisfatório das plantas (Grattapaglia \& Machado, 1998; Carvalho Filho et al., 2002; Leal et al., 2007).

A eliminação da etapa do enraizamento in vitro é desejável do ponto de vista econômico, pois reduz os custos de mão de obra, infraestrutura, espaço da sala de crescimento, energia elétrica e meio de cultura, além de produzir plantas aclimatizadas em curto período (Grattapaglia \& Machado, 1998; Malda et al., 1999). Segundo esses autores, o enraizamento ex vitro, diretamente no substrato, produz um sistema radicular mais desenvolvido e funcional, com maior número de raízes secundárias, sem a formação intermediária de calo, que dificulta a conexão do sistema vascular entre caule e raiz, o que pode garantir uma alta porcentagem de sobrevivência após a transferência para as condições ex vitro.

Portanto, o objetivo deste trabalho foi analisar o efeito de diferentes substratos e do enraizamento, na aclimatização de plantas de Melocactus glaucescens, propagadas in vitro.

\section{MATERIAL E MÉTODOS}

\section{Efeito do substrato na aclimatização dos brotos obtidos in vitro}

Os brotos de M. glaucescens, com 120 dias, foram obtidos por organogênese direta em meio Murashige e Skoog (MS) (Murashige \& Skoog 1962), suplementado com 30 g L $^{-1}$ de sacarose, a partir da fragmentação de plantas germinadas in vitro.

Para o enraizamento, os brotos com 5-10 mm foram inoculados em tubo de ensaio ( 25 x $150 \mathrm{~mm}$ ), contendo 15 $\mathrm{mL}$ de meio de cultura MS, com metade da concentração salina, suplementado com $15 \mathrm{~g} \mathrm{~L}^{-1}$ de sacarose.

Após 30 dias, as raízes foram lavadas para remover o meio de cultura aderido, e, posteriormente, as plantas foram transferidas para recipientes plásticos de $50 \mathrm{~mL}$, contendo $45 \mathrm{~mL}$ dos substratos: terra vegetal (T1), terra vegetal e areia lavada (2:1) (T2) e terra vegetal e areia lavada (1:1) (T3).

As plantas foram mantidas em canteiros, sob $100 \%$ de luminosidade, com regas diárias, utilizando-se borrifador, e, a cada 7 dias, foram realizadas regas com $8 \mathrm{~mL}$ de água. Aos 75 dias, foram avaliados a porcentagem de sobrevivência (\%S); o diâmetro da parte aérea (DPA), medido transversalmente, considerando-se a maior largura do cladódio; o comprimento da parte aérea (CPA), medido da base do cladódio até o ápice; o comprimento da maior raiz (CR) e a massa seca total (MST). Essas variáveis foram avaliadas com auxílio de paquímetro digital $(150 \mathrm{~mm})$, para 
DPA e CPA e régua milimetrada, para CR. A massa seca foi determinada após secagem em estufa com ventilação forçada, a $60^{\circ} \mathrm{C}$, por 72 horas.

\section{Efeito de diferentes períodos de enraizamento na aclimatização dos brotos obtidos in vitro}

Os brotos de $M$. glaucescens com 210 dias foram obtidos por organogênese direta em meio MS (Murashige \& Skoog 1962), suplementado com $30 \mathrm{~g} \mathrm{~L}$ ${ }^{1}$ de sacarose, a partir da fragmentação de plantas germinadas in vitro.

Para avaliar o efeito dos diferentes períodos de enraizamento na aclimatização, os brotos foram submetidos a 4 tratamentos: (T1) dessecados em temperatura ambiente por 4 dias e transferidos para recipientes plásticos de $50 \mathrm{~mL}$, contendo $45 \mathrm{~mL}$ do substrato terra vegetal e areia lavada (1:1); transferidos para tubo de ensaio (25 x $150 \mathrm{~mm}$ ), contendo $15 \mathrm{~mL}$ de meio de cultura MS, com metade da concentração salina, suplementado com 15 g $\mathrm{L}^{-1}$ de sacarose por: 8 (T2), 16 (T3) e 23 (T4) dias. Após o período in vitro, os brotos, submetidos aos tratamentos 2, 3 e 4, foram retirados, e, quando na presença de raízes, estas foram lavadas para remover todo o meio de cultura aderido. As plantas foram transferidas para recipientes de $50 \mathrm{~mL}$, contendo $45 \mathrm{~mL}$ do substrato: terra vegetal e areia lavada (1:1).

Antes da transferência para o substrato, foram avaliados o diâmetro e comprimento da parte aérea (DPA e CPA) e a porcentagem de brotos que produziram raízes (\%R), em todos os tratamentos.

Após a transferência para o substrato, as plantas foram mantidas em canteiros, sob 100\% de luminosidade, com regas diárias, utilizando-se borrifador e, a cada 7 dias, foram realizadas regas com $8 \mathrm{~mL}$ de água. Aos 75 dias, foram avaliados a porcentagem de sobrevivência (\%S); o diâmetro e o comprimento da parte aérea (DPA e CPA); o comprimento da maior raiz (CR); a porcentagem de brotos que produziram raiz (\%R) e a massa seca total (MST).

Todos os meios de cultura utilizados nesse trabalho foram gelificados com 6,5 g L ${ }^{-1}$ de ágar, esterilizados quimicamente, segundo a metodologia de Teixeira et al. (2006), e o $\mathrm{pH}$ foi ajustado a 5,7. Os tubos de ensaio foram fechados com película de polivinilcloreto (PVC).

As culturas in vitro foram mantidas a $25 \pm 3{ }^{\circ} \mathrm{C}$, sob luz fluorescente com radiação fotossintética ativa de 60 $\mu \mathrm{mol} . \mathrm{m}^{-2} . \mathrm{s}^{-1}$ e fotoperíodo de16 horas.

Para ambos os experimentos, o delineamento experimental foi inteiramente casualizado, com dez repetições e três plantas por repetição (uma planta por recipiente).

Os dados foram submetidos à análise de variância, utilizando-se o programa estatístico Sisvar 4.3 (Ferreira, 2003). As médias foram comparadas pelo teste de ScottKnott, a 5\% de probabilidade.

\section{RESULTADOS E DISCUSSÃO}

\section{Efeito do substrato na aclimatização dos brotos obtidos in vitro}

Os valores observados para a sobrevivência das plantas aclimatizadas sob 100\% de luminosidade, nos diferentes substratos, foram superiores a 93\%, não havendo diferença significativa entre os tratamentos (Tabela 1). Essas altas taxas de sobrevivência indicam que a etapa de rustificação dos brotos enraizados não é necessária para M. glaucescens, o que reduz o tempo in vitro e demonstra que a mudança do metabolismo heterotrófico para o autotrófico não é um fator limitante para a aclimatização dessa espécie (Tabela 1).

Esses resultados discordam de Rout et al. (2006), que afirmam ser necessário haver uma aclimatização gradual, das plantas micropropagadas, do ambiente de alta umidade e baixa irradiância para um ambiente inverso, capacitando essas plantas a sobreviver sob condições climáticas adversas. Segundo esses autores, as plantas crescidas in vitro são expostas a condições controladas, como altas quantidades de nutrientes inorgânicos e orgânicos, alta umidade, baixa luminosidade e poucas trocas gasosas, promovendo rápido crescimento e multiplicação, porem induz mudanças estruturais e fisiológicas nas plantas que podem dificultar sua sobrevivência, quando transferidas diretamente para o campo.

A rustificação é a etapa da micropropagação que induz modificações morfofisiológicas nas plantas, o que aumenta sua sobrevivência durante a transferência do cultivo in vitro para as condições ex vitro (Santana, 2003).

As espécies da família Cactaceae possuem características especializadas para sobreviverem em ambientes áridos, tais como, a presença de espinhos, de cera, de parênquima aquífero, de sistema radicular fasciculado e de Mecanismo Ácido das Crassuláceas (CAM), que reduzem a perda de água (Sriskandarajah \& Serek, 2004; Arruda et al., 2005; Khalafalla et al., 2007). Essas características podem ter favorecido a independência da etapa de rustificação e os valores altos para a sobrevivência nas condições ex vitro. Malda et al. (1999) observaram que a perda de água após 20 dias de aclimatização não afetou a sobrevivência dos cactos Coryphanta mínima e Obregonia denegrii, e que, após esse período, as plantas iniciaram um processo de recuperação.

Na avaliação do crescimento das plantas na aclimatização de $M$. glaucescens, não houve diferença significativa para \%S, DPA e CPA, nos três diferentes tipos de substratos (Tabela 1). No entanto, o substrato terra vegetal e areia (1:1), foi, em geral, mais eficiente, visto que os resultados observados para a variável CR e MST foram significativamente maiores (30,53 mm e 46,80 mg), do que os observados nos demais substratos (Tabela 1). O maior 
valor para CR, no substrato contendo a maior porcentagem de areia, pode estar relacionado com a menor disponibilidade de nutrientes com relação aos demais substratos testados, o que estimularia o maior crescimento em comprimento da raiz em busca de nutrição (Cavalcanti \& Resende, 2006).

Os resultados obtidos para as variáveis CR e MST demonstraram que o substrato adequado para o crescimento, na etapa da aclimatização das plantas micropropagadas de M. glaucescens, deve conter 50\% de terra vegetal e $50 \%$ de areia lavada. A maior porcentagem de areia nesse substrato pode ter favorecido o melhor desenvolvimento das plantas, já que suas propriedades físicas possibilitam uma maior aeração e permeabilidade do solo, o que fornece condições para melhor enraizamento (Cavalcanti \& Resende, 2006; Lone et al., 2007).

\section{Efeito de diferentes períodos de enraizamento na aclimatização dos brotos obtidos in vitro}

Na avaliação realizada antes da transferência para o substrato, os valores, para as variáveis DPA e CPA dos brotos que foram mantidos in vitro após a excisão (T2, T3 e T4), foram superiores aos observados para os brotos que foram diretamente transferidos para o substrato (T1). Os brotos transferidos aos 8 (T2), 16 (T3) e 23 (T4) dias apresentaram maiores valores para o DPA, que correspondeu a um aumento de $23,40,34,75$ e $46,10 \%$, respectivamente, em comparação com os observados em T1, enquanto, para CPA, o aumento foi de 29,78, 45,76 e 63,68\% (Tabela 2).

As raízes surgiram a partir da $3^{\mathrm{a}}$ semana, apenas em $\mathrm{T} 3$ e T4, em que os valores para a variável \%R no $16^{\circ}$ dia foi de $80 \%$, sendo significativamente menor quando compa- rado com os valores obtidos no $23^{\circ}$ dia (96,67\%) (Tabela 2). O período para o início do enraizamento in vitro em meio sem regulador vegetal varia entre as diferentes espécies de cactos, como observado em Ariocarpus kotschoubeyanus (15a semana), Mammillaria sanangelensis ( $2^{\mathrm{a}}-3^{\mathrm{a}}$ semana), Turbinicarpus laui ( $2^{\mathrm{a}}$ semana) (Mata-Rosas et al., 2001; Rubluo et al., 2002; MoebiusGoldammer et al., 2003).

Com relação à sobrevivência das plantas aclimatizadas, para os tratamentos T2, T3 e T4 (90,00, 86,67 e 86,67\%, respectivamente) não houve diferença significativa, enquanto T1 (63,33\%) apresentou valores significativamente menores (Tabela 3). Esses resultados discordam dos encontrados por Medeiros et al. (2006), que não observaram crescimento dos brotos não enraizados de Notocactus magnificus e apenas $20 \%$ dos brotos enraizados sobreviveram no ambiente ex vitro.

Resultados semelhantes para sobrevivência de plantas regeneradas in vitro em condições ex vitro foram observados para espécies de cactos A. kotschoubeyanus (95-100\%), Escobaria mínima (92\%), Ferocactus acanthodes (90\%), Mammillaria pectinifera $(76,3 \%)$, Melocactus curvispinus (75\%), Opuntia ellisiana (100\%), Pelecyphora aselliformis (81,3\%), Pilosocereus robinii (66\% e 91,6\%) e Turbinicarpus laui (94-100\%) (Ault \& Blackmon, 1987; Mata-Rosas et al., 2001; Juárez \& Passera, 2002; Moebius-Goldammer et al., 2003; Khalafalla et al., 2007; Retes-Pruneda et al., 2007; Quiala et al., 2009).

A menor sobrevivência das plantas ex vitro, observada em $\mathrm{T} 1$, pode estar relacionada com os menores valores observados para as variáveis DPA e CPA analisadas, antes da transferência desses brotos para o substrato ou da

Tabela 1. Avaliação das plantas micropropagadas de Melocactus glaucescens em diferentes substratos após 75 dias da transferência para condição ex vitro. \%S= Porcentagem de sobrevivência; DPA e CPA=diâmetro e comprimento da parte aérea; CR= Comprimento da maior raiz; MST= Massa seca total

\begin{tabular}{|c|c|c|c|c|c|c|}
\hline \multicolumn{2}{|c|}{ Substrato } & \multirow{2}{*}{$\% \mathrm{~S}$} & \multirow{2}{*}{ DPA (mm) } & \multirow{2}{*}{$\mathrm{CPA}(\mathrm{mm})$} & \multirow{2}{*}{ CR (mm) } & \multirow{2}{*}{ MST (mg) } \\
\hline Terra vegetal & Areia & & & & & \\
\hline $100 \%$ & $0 \%$ & $93,33 a$ & $7,11 \mathrm{a}$ & 6,39a & $25,33 b$ & $25,80 \mathrm{~b}$ \\
\hline $75 \%$ & $25 \%$ & $93,33 a$ & $7,06 a$ & $6,46 a$ & $24,50 \mathrm{~b}$ & $28,50 \mathrm{~b}$ \\
\hline $50 \%$ & $50 \%$ & $96,67 a$ & $7,46 \mathrm{a}$ & $6,63 a$ & 30,53a & $46,80 \mathrm{a}$ \\
\hline
\end{tabular}

Médias seguidas pela mesma letra nas colunas não diferem significativamente entre si pelo teste Scott-Knott $(\mathrm{p}<0,05)$.

Tabela 2. Avaliação dos brotos micropropagados de Melocactus glaucescens mantidos in vitro, antes da transferência para o substrato. DPA e CPA=diâmetro e comprimento da parte aérea; \%R= porcentagem de brotos que produziram raiz

\begin{tabular}{lccc}
\hline Transferência & DPA $(\mathbf{m m})$ & CPA $(\mathbf{m m})$ & \% \\
\hline T1 & $4,23 \mathrm{c}$ & $4,13 \mathrm{~b}$ & $0 \mathrm{c}$ \\
T2 (8 dias) & $5,22 \mathrm{~b}$ & $5,36 \mathrm{a}$ & $0 \mathrm{c}$ \\
T3 (16 dias) & $5,70 \mathrm{~b}$ & $6,02 \mathrm{a}$ & $80,00 \mathrm{~b}$ \\
T4 (23 dias) & $6,18 \mathrm{a}$ & $6,76 \mathrm{a}$ & $96,67 \mathrm{a}$
\end{tabular}

Médias seguidas pela mesma letra nas colunas não diferem significativamente entre si pelo teste $\mathrm{Scott}-\mathrm{Knnott}(\mathrm{p}<0,05)$.

Rev. Ceres, Viçosa, v. 57, n.6, p. 803-809, nov/dez, 2010 
dessecação excessiva desses brotos após a excisão do explante (Tabelas 2 e 3). O período de desidratação possibilita a perda de água acumulada em excesso durante o cultivo in vitro, o que evita o apodrecimento das raízes nas condições ex vitro (Ramirez-Malagon et al., 2007). Para as espécies de cactos, a presença de uma matriz parenquimática, que permite a distensão e retração do corpo vegetativo, dependendo da disponibilidade de água, permite que tenham capacidade de se reidratar após o cultivo in vitro (Mauseth, 1993; Malda et al., 1999; Khalafalla et al., 2007). No entanto, o tempo de dessecação a que os brotos de $M$. glaucescens foram submetidos nesse trabalho, pode ter sido prejudicial.

Os maiores valores observados do DPA e CPA, antes da transferência para o substrato em T2, T3 e T4, refletiram-se nos valores encontrados na avaliação do crescimento ex vitro, que mostraram um aumento entre 54,50 e 82,56\% para DPA e 58,43 e 103,09\% para CPA, em comparação a T1.

Para o CR, os valores observados em T2, T3 e T4 (16,63, 19,00 e 21,30 mm) não apresentaram diferença significativa e foram superiores a T1 (10,67 mm). O mesmo comportamento ocorreu para a variável \%R, em que, para T2, T3 e T4, os valores variaram entre 83,33 e 90\% e em T1 63,33\% (Tabela 3).

Esses resultados demonstram que, para o enraizamento e aclimatização de $M$. glaucescens, não é necessário o tratamento da planta e do substrato com fungicida, o que discorda dos resultados observados por Ramirez-Malagon et al. (2007), que demonstraram que esses tratamentos são fundamentais para espécies de cactos, por causa do apodrecimento das raízes, que ocorre no processo de aclimatização das plantas micropropagadas.

O enraizamento ex vitro dos brotos de M. glaucescens, em T1 e T2, sem nenhum tratamento, demonstra que estes são capazes de emitir raízes, independentemente da condição de cultivo, assim como relatado por Ault e Blackmon (1987), que observaram 90\% de sobrevivência após transferência para as condições ex vitro dos brotos não enraizados de Ferocactus acanthodes. Malda et al. (1999) relataram, para C. mínima e O. denegrii, não haver diferença na aclimatização dessas espécies, quando enraizadas in vitro e ex vitro. Pérez-Molphe-Balch et al. (1998), ao estudarem 21 espécies de cactos, observaram uma porcentagem de sobrevivência, ex vitro, variando de 50 a 95\%, alcançada por brotos não enraizados, tratados nas condições ex vitro com uma mistura para enraizamento comercial. Os resultados observados neste trabalho discordam dos observados por RodríguezGaray \& Rubluo (1992) que observaram uma deficiência no enraizamento in vitro dos brotos regenerados de Aztekium ritteri.

A formação de raízes in vitro e ex vitro em $M$. glaucescens, sem a necessidade da utilização de regulador vegetal, indica que a concentração dos hormônios endógenos é suficiente para promover a formação das raízes dos brotos nessa espécie. Os cactos, em geral, produzem um excesso de auxina sob condições de cultivo in vitro, que pode favorecer a formação de raízes em meio livre de regulador vegetal (Hubstenberger et al., 1992; Sriskandarajah \& Serek, 2004).

Resultados semelhantes, em que os brotos desenvolveram raízes sem tratamento com regulador vegetal, foram relatados para A. kotschoubeyanus, C. mínima, F. acanthodes, Mammillaria carmenae, N. magnificus, $O$. denegrii, P. robinii, T. laui (Ault \& Blackmon, 1987; Malda et al., 1999; Mata-Rosas et al., 2001; Moebius-Goldammer et al., 2003; Medeiros et al., 2006; Retes- Pruneda et al., 2007; Quiala et al., 2009).

Estudos com espécies de cactos, em que o melhor tratamento para o enraizamento ocorreu sem adição de regulador vegetal e na presença de carvão, foram relatados para Echinocereus schmollii (72,2\%) e Escontria chiotilla (100\%) (Retes-Pruneda et al., 2007).

Entretanto, o enraizamento com o uso de reguladores vegetais ocorre para algumas espécies de cactos. Frota et al. (2004) observaram, para Opuntia ficus-indica, que os melhores resultados ocorreram na concentração de $5 \mathrm{mg}$ $\mathrm{L}^{-1}$ de ácido indolacético (AIA). Escobar et al. (1986), ao estudarem diferentes concentrações de ácido indolbutírico (AIB) no enraizamento de Opuntia amyclaea, observaram que as raízes mais longas e com maior rapidez no crescimento ocorreram na presença de AIB a $5 \mu \mathrm{M}$. Khalafalla et al. (2007), ao estudarem em O. ficus-indica diferentes tipos (AIB, ácido naftaleno acético-ANA e ácido indolacético-AIA) e concentrações ( $(0,00,0,25,0,50$ e

Tabela 3. Avaliação das plantas micropropagadas de Melocactus glaucescens após 75 dias da transferência para as condições ex vitro. \%S= Porcentagem de sobrevivência; DPA e CPA=diâmetro e comprimento da parte aérea; CR= Comprimento da maior raiz; \%R= porcentagem de brotos que produziram raiz; MST= Massa seca total

\begin{tabular}{lcccccc}
\hline Transferência & \% S & DPA $(\mathbf{m m})$ & $\mathbf{C P A}(\mathbf{m m})$ & $\mathbf{C R}(\mathbf{m m})$ & $\mathbf{\%} \mathbf{R}$ & MST (mg) \\
\hline T1 & $63,33 \mathrm{~b}$ & $3,67 \mathrm{~b}$ & $3,56 \mathrm{~b}$ & $10,67 \mathrm{~b}$ & $63,33 \mathrm{~b}$ & $14,41 \mathrm{a}$ \\
T2 (8 dias) & $90,00 \mathrm{a}$ & $5,67 \mathrm{a}$ & $5,64 \mathrm{a}$ & $16,63 \mathrm{a}$ & $90,00 \mathrm{a}$ & $15,35 \mathrm{a}$ \\
T3 (16 dias) & $86,67 \mathrm{a}$ & $5,39 \mathrm{a}$ & $5,62 \mathrm{a}$ & $19,00 \mathrm{a}$ & $83,33 \mathrm{a}$ & $22,95 \mathrm{a}$ \\
T4 (23 dias) & $86,67 \mathrm{a}$ & $6,70 \mathrm{a}$ & $7,23 \mathrm{a}$ & $21,30 \mathrm{a}$ & $86,67 \mathrm{a}$ & $27,15 \mathrm{a}$ \\
\hline
\end{tabular}

Médias seguidas pela mesma letra nas colunas não diferem significativamente entre si pelo teste Scott-Knott $(\mathrm{p}<0,05)$. 
1,00 $\mathrm{mg} \mathrm{L}^{-1}$ ) de auxinas, observaram 100\% de enraizamento em meio sem regulador vegetal, e que, no meio contendo $0,5 \mathrm{mg} \mathrm{L}^{-1}$ de AIA, e nos demais tratamentos, os valores variaram de 50 a 83,3\%. Valores de $100 \%$ de enraizamento foram observados para Opuntia ellisiana na presença do AIB a 25 e 50 $\mu$ M (Juárez \& Passera, 2002). Retes-Pruneda et al. (2007), ao utilizar 0,5 $\mathrm{mg} \mathrm{L}^{-1}$, observaram 93,7\% de enraizamento em Melocactus curvispinus.

Os resultados encontrados em ambos os experimentos demonstram que as plantas de M. glaucescens podem ser aclimatizadas diretamente em ambiente sob 100\% de luminosidade, assim como relatado por Juárez \& Passera (2002) para a espécie O. ellisiana.

Tendo em vista que os brotos, em T2, foram transferidos para o substrato sem raiz e obtiveram $90 \%$ de sobrevivência e de porcentagem de enraizamento ex vitro, e que os valores para estas variáveis, em T1, foram significativamente menores que nos demais tratamentos (63,33\%), sugere-se que os brotos com o DPA e CPA acima de $5 \mathrm{~mm}$ podem ser transferidos sem a etapa de enraizamento in vitro. Entretanto, estudos devem ser realizados para investigar o tempo de dessecação antes da transferência para o substrato, já que este também pode ter sido um fator que levou a valores baixos para \%S em T1. Pérez-Molphe-Balch et al. (1998) afirmam que brotos de espécies de cactos com tamanho acima de 5 mm são apropriados para o enraizamento.

A restauração da competência de enraizamento, como observado nos tratamentos T1 e T2, é considerada sinônimo de rejuvenescimento na micropropagação, o que pode indicar o sucesso na etapa de aclimatização (Grattapaglia \& Machado, 1998).

Na análise da MST, não houve diferença significativa entre os tratamentos e os valores variaram de 14,41 a $27,15 \mathrm{mg}$.

O menor valor para \%S no experimento 2 (86,67 a 90\%), em comparação com o 1 (96,67\%), pode estar relacionado com um aumento na temperatura e, consequentemente, menor disponibilidade de água, decorrente da época do ano, já que o experimento 1 foi conduzido entre junho e agosto de 2009, enquanto o segundo foi conduzido entre setembro e dezembro de 2009.

\section{CONCLUSÕES}

É possível a aclimatização de plantas micropropagadas de $M$. glaucescens, sendo adequada a utilização do substrato, contendo $50 \%$ de terra vegetal e $50 \%$ de areia lavada.

O tamanho mínimo do DPA e CPA para transferência para as condições ex vitro é de 5 mm.

As etapas do enraizamento in vitro e rustificação podem ser eliminadas da micropropagação de $M$. glaucescens.

\section{AGRADECIMENTOS}

À Coordenação de Aperfeiçoamento de Pessoal de Nível Superior (CAPES) pela concessão da bolsa.

\section{REFERÊNCIAS}

Arruda E, Melo-de-Pinna GF \& Alves M (2005) Anatomia dos órgãos vegetativos de Cactaceae da caatinga pernambucana. Revista Brasileira de Botânica, 28:589-601.

Ault JR \& Blackmon WJ (1987) In vitro propagation of Ferocactus acanthodes (Cactaceae). Hort Science, 22:126-127.

Barboza SBSC, Graciano-Ribeiro D, Teixeira JB, Portes TA \& Souza LAC (2006) Anatomia foliar de plantas micropropagadas de abacaxi. Pesquisa Agropecuária Brasileira, 41:185-194.

Carvalho Filho JLS, Arrigoni-Blank MF, Blank AF, Santos-Neto AL \& Amâncio VF (2002) Produção de mudas de Cassia grandis L. em diferentes ambientes, recipientes e misturas de substratos. Revista Ceres, 40:341-352.

Cavalcanti NB \& Resende GM (2006). Efeito de diferentes substratos no desenvolvimento do mandacaru sem espinhos (Cereus hildemannianus K. Schum). Revista Caatinga, 19:255260.

Escobar HA, Villalobos, VM \& Villegas A (1986) Opuntia micropropagation by axillary proliferation. Plant Cell Tissue and Organ Culture, 7:269-277.

Estrada-Luna AA, Martínez-Hernández JJ, Torres-Torres ME \& Chablé-Moreno F (2008) In vitro micropropagation of the ornamental prickly pear cactus Opuntia lanigera Salm-Dyck and effects os sprayed $\mathrm{GA}_{3}$ after transplantation to ex vitro conditions. Scientia Horticulturae, 117:378-385.

Ferreira DF (2003) SISVAR Sistema de analises estatísticas. Versão 4.3. Lavras, UFLA. CD-ROM

Fonseca RBS (2004) Fenologia reprodutiva e dispersão de Melocactus glaucescens Buining \& Brederoo e M. paucispinus G. Heimen \& R. Paul (Cactaceae) no Município de Morro do Chapéu, Chapada Diamantina - Bahia- Brasil. Dissertação de Mestrado. Universidade Estadual de Feira de Santana, Feira de Santana. 123p.

Frota HM, Carneiro, MSS, Llamoca-Zárate RM, Campos FAP \& Peixôto MJA (2004) Proliferação e enraizamento in vitro de brotos de palma forrageira-Opuntia ficus-indica (L.) MILL Acta Scientiarum Biological Sciences, 26:235-238.

Grattapaglia D \& Machado MA (1998) Micropropagação. In: Torres AC, Caldas LS \& Buso JA (Eds.) Cultura de tecidos e transformação genética de plantas v.1. Brasília, EMBRAPASPI/ EMBRAPA-CNPH. p.183-260.

Hubstenberger JF, Clayton PW \& Phillips GC (1992) Micropropagation of Cacti. In: Bayay YPS (Ed.) Biotechnology in Agriculture and Forestry v 20. Berlin, Springer- Verlag. p.4968.

IUCN (2010) IUCN Red List of Threatened Species. Version 2010.2. Disponível em: <http: //www.iucnredlist.org. Acessado em: 25 de julho de 2010 .

Juárez MC \& Passera CB, (2002) In vitro propagation of Opuntia ellisiana Griff. and acclimatization to field conditions. Biocell, 26:319-324.

Khalafalla MM, Abdellatef E, Mohamed-Ahmed MM \& Osman MG (2007) Micropropagation of cactus (Opuntia ficus-indica) as strategic tool to combat desertification in arid and semi arid regions. Int. J. Sustain. Crop Production, 2:1-8. 
Lambert SM, Borba EL, Machado MC \& Andrade SCS (2006a) Allozyme diversity and morphometrics of Melocactus paucispinus (Cactaceae) and evidence for hybridization with $M$. concinnus in the Chapada Diamantina, North-eastern Brazil. Annals of Botany, 97:389-403.

Lambert SM, Borba EL \& Machado MC (2006b) Allozyme diversity and morphometrics of Melocactus glaucescens (Cactaceae) and investigation of the putative hybrid origin of Melocactus xalbicephalus (Melocactus ernestii X M. glaucescens) in northeastern Brazil. Plant Species Biology, 21:93-108.

Leal L, Biondi D \& Nunes JRS (2007) Propagação por sementes de Schlumbergera truncata (Haw.) Moran (flor-de-maio) em diferentes substratos. Acta Scientiarum Biological Sciences, 29:277-280.

Lone AB, Takahashi LSA, Faria RT \& Destro D (2009) Desenvolvimento vegetativo de Melocactus bahiensis (Cactaceae) sob diferentes níveis de sobreamento. Revista Ceres, 56:199-203.

Machado MC (2009) The genus Melocactus in eastern Brazil: part I - an introduction to Melocactus. British Cactus \& Succulent Journal, 27:1-16.

Malda BG, Backhaus RA \& Martin C (1999) Alterations in growth and crassulacean acid metabolism (CAM) activity of in vitro cultured cactus. Plant Cell Tissue and Organ Culture, 58:1-9.

Mata-Rosas M, De La Rosa MAM, Moebius-Goldammer K \& Chávez-Avila VM (2001) Micropropagation of Turbinicarpus laui Glass et Foster, an endemic and endangered species. In vitro Cellular and Developmental Biology-Plant, 37:400-404.

Mauseth JD (1993) Water-storing and Cavitation-preveting adaptations in wood of cacti. Annals of Botany, 72:81-89.

Medeiros LA, Salvador RCS, Gallo LA, Oliveira ET \& Demattê MESP (2006) In vitro propagation of Notocactus magnificus. Plant Cell Tissue and Organ Culture, 84:165-169.

MMA (2008) Lista Oficial das Espécies da Flora Brasileira Ameaçadas de Extinção. Ministério do Meio Ambiente. Disponível em: <http://www.mma.gov.br>. Acessado em: 15 de novembro de 2008.

Moebius-Goldammer KG, Mata-Rosas M \& Chávez-Avila VM (2003) Organogenesis and somatic embryogenesis in Ariocarpus kotschoubeyanus (Lem.) K. Schum. (Cactaceae), an endemic and endangered Mexican species. In vitro Cellular and Developmental Biology-Plant, 39:388-393.

Moreira MA, Carvalho JG, Pasqual M, Fráguas CB \& Silva A (2006) Efeito de substratos na aclimatização de mudas micropropagadas de abacaxizeiro cv. Pérola. Ciência e Agrotecnologia, 30:875879 .

Murashige T \& Skoog F (1962) A revised medium for rapid growth and bioassays with tobacco tissue cultures. Phsysiology Plantarum, 15:473-497.
Pérez-Molphe-Balch E, Reyes MEP, Amador EV, Rangel EM, Ruiz LRM \& Viramontes HJL (1998) Micropropagation of 21 species of Mexican cacti by axillary proliferation. In vitro Cellular and Developmental Biology- Plant, 34:131-135.

Quiala E, Matos J, Montalvo G, Feria M, Chávez M., Capote A, Pérez N, Barbón R \& Kowalski B (2009) In vitro propagation of Pilosocereus robinii (Lemaire) Byles et Rowley, endemic and endangered cactus. Journal of the Professional Association for Cactus Development, 11:18-25.

Ramirez-Malagon R, Aguillar-Ramirez I, Borodanenko A, PerezMoreno L, Barrera-Guerra JL, Nuñez-Palenius HG \& OchoaAlejo N (2007) In vitro propagation of ten threatened species of Mammillaria (Cactaceae). In vitro Cellular and Developmental Biology-Plant, 43:660-665.

Retes-Pruneda JL, Valadez-Aguilar ML, Pérez-Reyes ME \& PérezMolphe-Balch E (2007) Propagación in vitro de especies de Echinocereus, Escontria, Mammillaria, Melocactus y Polaskia (Cactaceae). Boletín de la Sociedad Botánica de México, 81:9-16.

Rocha MAC da, Costa MAP de, Silva AS, Ledo CAS, Moreira MJS \& Bastos LP (2008) Enraizamento in vitro e aclimatização de genótipos de jenipapeiro (Genipa americana L.). Revista Brasileira de Fruticultura, 30:769-774

Rodríguez-Garaz B \& Rubluo A (1992) In vitro morphogenetic responses of the endangered cactus Aztekium ritteri (Boedeker). Cactus and Succulent Journal, 64:116-119.

Rout GR, Mohapatra A \& Mohan Jain S (2006) Tissue culture of ornamental pot plant: A critical review on present scenario and future prospects. Biotechnology Advances, 24:531-560.

Rubluo A, Marín-Hernández T, Duval K, Vargas A \& MárquezGuzmán J (2002) Auxin induced morphogenic responses in longterm in vitro subcultured Mammillaria san-angelensis SánchezMejorada (Cactaceae). Scientia Horticulturae, 95:341-349.

Santana JRF (2003) Controle da morfogênese in vitro em algumas espécies de Annonaceae. Tese de doutorado. Universidade Federal de Lavras, Lavras. 237p.

Sriskandarajah S \& Serek M (2004) Regeneration from phylloclade explants and callus cultures of Schlumbergera e Rhipsalidopsis. Plant Cell Tissue and Organ Culture, 78:75-81.

Taylor NP (2000) Cacti of eastern Brazil. Royal Botanic Gardens, Kew. Taxonomy and Phytogeography of the Cactaceae of Eastern Brazil. Thesis for the award of 'Doctor of Philosophy'. Royal Botanic Gardens, Kew. 414p.

Taylor NP \& Zappi DC (2004) Cacti of Eastern Brazil. Kew, Richmond, Surrey, UK: Royal Botanic Gardens. 499p.

Teixeira SL, Ribeiro JM \&Teixeira MT (2006) Influence of NaClO on nutrient medium sterilization and on pineapple (Ananas comosus cv Smooth cayenne) behavior. Plant Cell Tissue and Organ Culture, 86:375-378. 